\title{
Calidad del Agua para Actividades Recreativas del Río Hardy en la Región Fronteriza México-Estados Unidos
}

\author{
Socorro Romero(1) Jaqueline García ${ }^{(2)}$, Benjamín Valdez $^{(1)}$ y Miguel Vega ${ }^{(3)}$ \\ (1) Instituto de Ingeniería. Área de Medio Ambiente, Universidad Autónoma de Baja California, \\ Blvd. Benito Juárez y Calle de la Normal s/n Col. Insurgentes Este, Mexicali, B. C.-México. \\ (e-mail: romero@iing.mxl.uabc.mx) \\ (2) Centro de Investigación en Alimentación y Desarrollo. Carr. al Varadero Nal. km 6.6 \\ Guaymas, C.P. 85480 Sonora-México, (e-mail: jaquigarcia@yahoo.com.mx) \\ (3) Instituto de Investigaciones en Ciencias Veterinarias. Departamento de Toxicología, \\ Universidad Autónoma de Baja California. Km 13.5 Carr. a San Felipe, Mexicali, B. C.-México. \\ (e-mail: boat1970@hotmail.com)
}

Recibido Sept. 07, 2009; Aceptado Nov. 11, 2009; Versión Final recibida Abr. 15, 2010

\begin{abstract}
Resumen
Se evaluó la aptitud del agua del Río Hardy para actividades recreativas de acuerdo a normas de calidad de agua vigentes. Se fijaron quince sitios de muestreo donde mensualmente durante un año se colectaron muestras de agua, se determinó la concentración de Escherichia coli como indicador de calidad bacteriológica y se midieron in situ el pH, oxígeno disuelto, temperatura y conductividad eléctrica. De los quince sitios muestreados, cinco están designados para actividad recreativa con contacto primario. Los resultados muestran que en el periodo de actividad recreativa, sólo cinco sitios cumplieron con el límite máximo permisible de $126 \mathrm{NMP} / 100 \mathrm{~mL}$, de los cuales tres están designados para uso recreativo. La concentración de Escherichia coli se detectó en un intervalo entre 8 y 7100 $\mathrm{NMP} / 100 \mathrm{~mL}$. En el periodo de agosto a noviembre el agua del río estuvo contaminada en todos los sitios.
\end{abstract}

Palabras Clave: Escherichia coli, calidad del agua, contaminación del agua, calidad bacteriológica.

\section{Water Quality for Recreational Activities of the Hardy River in the Mexican-U.S. Border Region}

\begin{abstract}
This study was focused on the determination of the water quality in the Hardy River. The aptitude of the water for recreational uses was assessed according to the current standards. Fifteen sampling sites were established, of which five of these are designated for recreational primary activities. Water samples were collected and analyzed using the concentration of Escherichia coli as bacteriological quality indicator, and determining $\mathrm{pH}$, dissolved oxygen, temperature and electrical conductivity. Results show that only five sites meet the maximum allowable value of $126 \mathrm{NMP} / 100 \mathrm{~mL}$, three of them designated as recreational. The concentration of Escherichia coli was observed in a range of 8 to $7100 \mathrm{NMP} / 100 \mathrm{~mL}$. From august to november the water was polluted in all sites along the river.
\end{abstract}

Keywords: Escherichia coli, water quality, water pollution, bacteriological water 


\section{INTRODUCCIÓN}

El agua es un recurso importante para cualquier actividad humana y para los ecosistemas, sin embargo ésta es cada vez más escasa (Saracho et al., 2006). Otro problema que se enfrenta en la actualidad es el de la contaminación de los cuerpos de agua. En el caso de las aguas naturales la contaminación puede originarse por los propios organismos ambientales acuáticos, pero también puede provenir de los efluentes de aguas residuales o industriales, de las actividades agrícolas y ganaderas, o de animales que viven en el entorno acuático. Desde el punto de vista bacteriológico, el examen de la calidad sanitaria del agua tiene por objetivo determinar la presencia de ciertos grupos de bacterias, que revelen una contaminación por materia fecal o por materia orgánica. El uso recreativo del agua implica un riesgo de contraer enfermedades como la gastroenteritis, dermatitis y problemas respiratorios. Crystosporidium, norovirus y cepas de Escherichia coli enteropatógenas son las causas más importantes de brotes de diarrea, mientras que Pseudomonas y $S$. aureus son los principales agentes de infecciones cutáneas y Legionella de infecciones respiratorias (DoménechSánchez et al., 2008), situación que provoca un riesgo de contraer enfermedades en personas que realizan actividades recreativas que implican un contacto directo con el agua. Casi todos los estudios epidemiológicos enfocados a la contaminación de cuerpos de agua con aguas residuales domésticas han encontrado asociaciones entre los niveles de contaminación y la incidencia de síntomas (Dwight, 2004).

Las actividades de monitoreo son una herramienta para evaluar la calidad del agua y permiten determinar si un cuerpo de agua es apto para soportar los diferentes usos como vida acuática, recreación o pesca (Papovicova, 2008). Debido a la gran diversidad de microorganismos patógenos que se pueden encontrar en aguas contaminadas, al costo y a la dificultad para el análisis microbiológico en muestras de agua, frecuentemente se usan organismos indicadores para el monitoreo y la regulación de aguas recreativas. Los organismos indicadores se encuentran en la materia fecal en altas concentraciones y son más fáciles de medir que los organismos patógenos (Wade et al, 2006). Las bacterias indicadoras de contaminación bacteriológica no son necesariamente patógenas, pero su presencia indica contaminación con desechos humanos donde es muy probable que existan organismos patógenos. La bacteria $E$. coli ha sido utilizada por décadas como indicador bacteriano porque muestra una buena relación con las enfermedades gastrointestinales asociadas a la natación (Pruss, 1998).

El Río Hardy se localiza en la parte oeste del delta del Río Colorado en el estado de Baja California, México. Su cauce inicia en las coordenadas 32¹9'41.7” y $115^{\circ} 17^{\prime} 30.8^{\prime \prime}$. En el pasado, el Río Hardy recibía agua del Río Colorado, sin embargo, después de la construcción de las grandes presas en Estados Unidos, dejó de recibir agua de ese río y actualmente sólo recibe agua de retorno de los drenes agrícolas del Valle de Mexicali, agua residual doméstica de los poblados aledaños y de corrales de ganado porcino y vacuno, la cual es transportada por el Río Hardy y finalmente descargada al Golfo de California. A lo largo de los bancos del río, hay 16 campos turísticos que son usados por turistas de Mexicali y de los Estados Unidos en actividades de recreación. Por ello, la calidad del agua de este río es de gran interés y preocupación pública, por lo que, el presente estudio tuvo los siguientes propósitos: a) Realizar un análisis mensual del agua en 15 sitios del río, durante un año para conocer la calidad bacteriológica y físico-química del agua, b) determinar la variación espacial y temporal de la calidad bacteriológica (concentración de E. coli) y c) Evaluar si el agua del río cumple con las normas de calidad de agua para recreación (USEPA, 2004).

\section{METODOLOGÍA}

\section{Muestreo y análisis}

Se seleccionaron 15 sitios representativos para el estudio a lo largo del río (Fig. 1). Los primeros 6 sitios se ubicaron en la parte norte, donde se localizan los drenes de descarga de agua de retorno agrícola. Los sitios 7 al 11 corresponden a sitios designados para actividad recreativa con contacto primario y los sitios 12 al 15 se encuentran en la parte baja del río y en esta zona actualmente no se realizan actividades recreativas. De febrero de 2006 a enero de 2007, se colectaron muestras mensuales de agua en cada sitio a una profundidad de $0.3 \mathrm{~m}$ para el análisis de $E$. coli. 


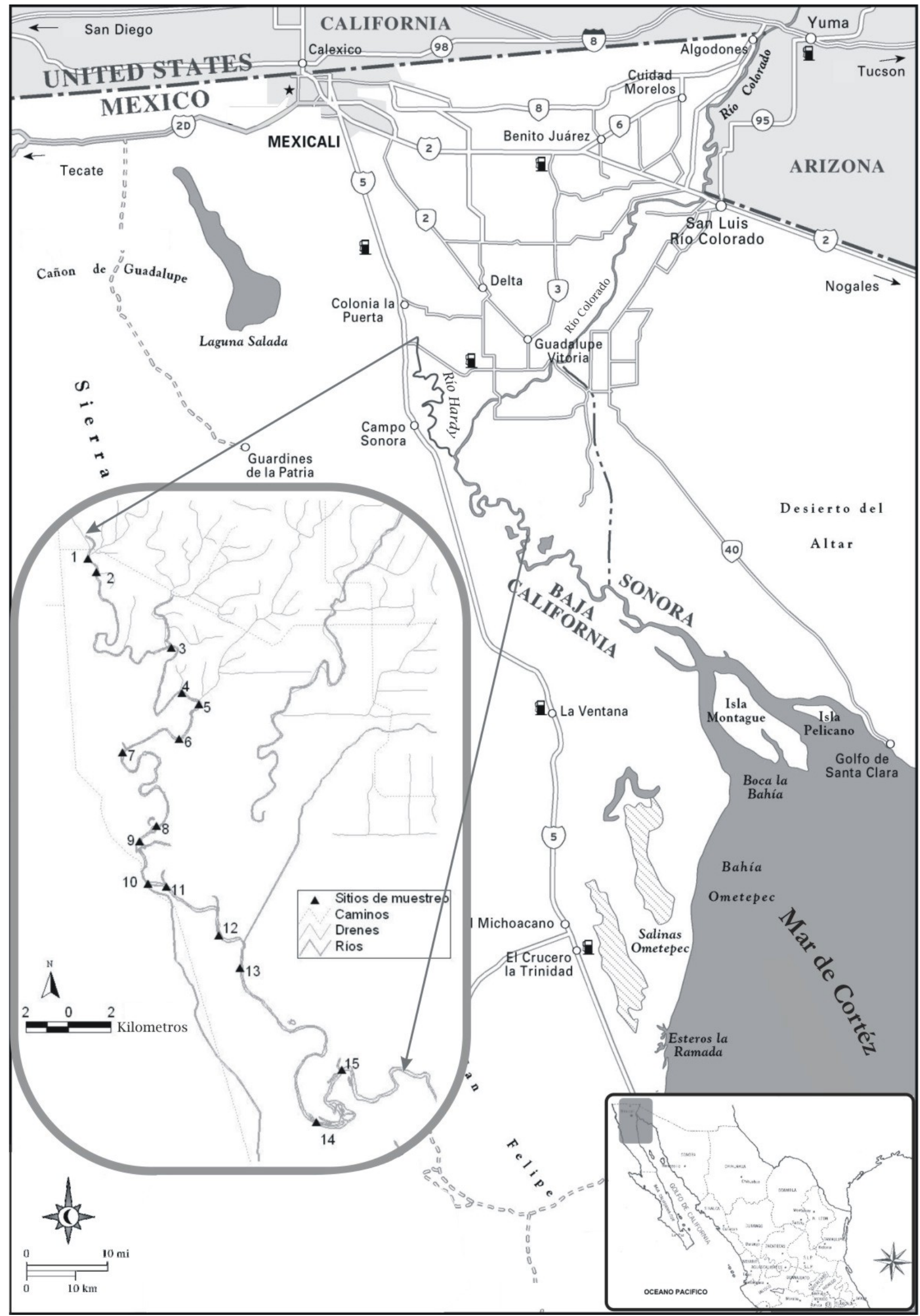

Fig. 1: Ubicación de los sitios de muestreo sobre el Río Hardy 
Durante la toma de muestras se midió in situ el $\mathrm{pH}$, la concentración de oxígeno disuelto [mg/L], la temperatura $\left[{ }^{\circ} \mathrm{C}\right]$ y la conductividad eléctrica $[\mathrm{mS} / \mathrm{cm}]$, usando una sonda Quanta ${ }^{\circledR}$ Hydrolab. Las muestras para el análisis de E. coli [NMP/100mL], se colectaron por duplicado en botellas de plástico esterilizadas de $120 \mathrm{~mL}$, se conservaron a $4{ }^{\circ} \mathrm{C}$ durante su traslado al laboratorio y se analizaron en un tiempo máximo de 6 horas utilizando el Método Colilert ${ }^{\circledR}$ (IDEXX, 2003), aprobado por la EPA (USEPA, 2007). Las muestras se analizaron por duplicado y se corrieron blancos como controles de calidad de los procedimientos analíticos.

\section{Análisis estadístico}

1. Se analizó la variación espacial y temporal de los datos a través de un ANOVA simple $(p<0.001)$ para todos los datos obtenidos durante el periodo de estudio y se hizo una comparación múltiple para evaluar el nivel de significancia. Asimismo se realizó un análisis de correlación de Pearson para buscar relaciones entre las variables físico-químicas y la concentración de $E$. coli. Todos los análisis fueron realizados mediante el programa Statística versión 6.

2. Se evaluó la aptitud del agua para actividades recreativas, comparando los resultados de $E$. coli con las normas de USEPA que establecen un valor límite máximo permisible (LMP) de 126 NMP/100 $\mathrm{mL}$ expresado como densidad media geométrica (DMG) de E. coli para actividades recreativas con contacto primario. Se ha establecido que es técnicamente apropiado calcular la DMG mensual o la DMG para un periodo recreativo, por ser de mayor importancia conocer a calidad del agua durante el periodo de mayor exposición al agua (USEPA, 2004). Para fines de este estudio, se calculó la DMG para un periodo de actividad recreativa el cual comprendió los meses de marzo a agosto del 2006. Con base a lo anterior se determinó un valor de DMG para cada sitio durante el periodo recreativo y se compararon con el valor límite antes mencionado.

\section{RESULTADOS Y DISCUSIÓN}

Nivel de cumplimiento de la norma para actividades recreativas

En la tabla 1 se presentan los valores de concentración de E. coli detectados en cada sitio. La concentración de E. coli a lo largo del Río Hardy, varió en un intervalo entre 8 y $7100 \mathrm{NMP} / 100 \mathrm{~mL}$. Se observa que en los sitios 1 y 2, se obtuvieron los valores más altos (7100 y 6510 NMP/100 mL respectivamente). Esta elevada contaminación se asocia a la presencia de heces fecales sobre la superficie del agua en estos sitios que provienen de una abundante población de aves que utilizan la vegetación de esta parte del río como área de descanso. A partir del sitio 3 al sitio 15 la concentración de $E$. coli se detectó en concentraciones abajo de 2870 NMP/100 mL.

También se presentan los valores estimados de DMG considerando para este cálculo solamente los datos que comprenden el periodo de actividad recreativa en el río (de marzo a agosto del 2006). Al comparar los resultados de concentración de E. coli con el LMP de $126 \mathrm{NMP} / 100 \mathrm{~mL}$, se observó que de los quince sitios sólo cinco sitios cumplieron con este límite y corresponden a los sitios 8, 9,10, 14 y 15, de los cuales, los sitios 8,9 y 10 son sitios designados para actividad recreativa, mientras que los sitios $1,2,3,4,5,6,7,11,12$ y 13 no cumplieron con el LMP y de éstos, los sitios 7 y 11 son sitios designados para actividad recreativa. Aunque los valores obtenidos de DGM para los sitios 7 y 11 (162 y 159 NMP/100 mL respectivamente) no se encontraron muy por arriba del valor del LMP de $126 \mathrm{NMP} / 100 \mathrm{~mL}$, es importante resaltar que en el sitio 11 (conocido como la poza) era común ver a los residentes establecidos en esta parte del río bañándose con mayor frecuencia durante el mes de agosto, y en este mes se detectó una concentración de $980 \mathrm{NMP} / 100 \mathrm{~mL}$. Esto significa que quienes se bañaron en los sitios 7 y 11, principalmente los bañistas del sitio 11 son los que tuvieron un mayor riesgo de contraer enfermedades.

\section{Variación espacial y temporal de concentración de E. coli}

La Fig. 2 muestra la concentración promedio anual de E. coli para cada sitio. De acuerdo al análisis estadístico, los valores promedio de E. coli en el sitio 1 (1966 NMP/100 mL) y sitio 2 (2172 NMP/100 
$\mathrm{mL})$ resultaron significativamente distintos $(0.001<\mathrm{p}<0.05)$ del resto de los sitios. Los sitios 3 al 15 no presentaron variación significativa y la concentración media de $E$. coli en este tramo se mantuvo en un intervalo entre 277 NMP/100 mL y 987 NMP/100 mL. La homogeneidad en los sitios 5 al 15 puede explicarse porque en ese tramo del río no hay descargas agrícolas.

Tabla 1: Resultados de Concentración de E. coli [NMP/100 mL] de febrero de 2006 a enero de 2007

\begin{tabular}{crrrrrrrrrrrrr}
\hline & Feb & Mar & \multicolumn{1}{c}{ Abr } & May & \multicolumn{1}{c}{ Jun } & Jul & Ago & Sep & Oct & Nov & Dic & Ene & \\
Sitio & 2006 & 2006 & 2006 & 2006 & 2006 & 2006 & 2006 & 2006 & 2006 & 2006 & 2006 & 2007 & DMG \\
\hline 1 & 1120 & 7100 & 1046 & 830 & 51 & 1046 & 2420 & 1733 & 573 & 1725 & 3730 & 4190 & 1894 \\
2 & 866 & 6510 & 1986 & 2419 & 411 & 1986 & 2420 & 2420 & 2410 & 1039 & 1710 & 4050 & 1988 \\
3 & 103 & 2870 & 250 & 488 & 105 & 1553 & 2420 & 1300 & 1107 & 968 & 110 & 1553 & 719 \\
4 & 102 & 2420 & 980 & 164 & 65 & 1733 & 86 & 770 & 1986 & 2030 & 261 & 1300 & 394 \\
5 & 71 & 1986 & 233 & 580 & 43 & 1414 & 344 & 980 & 1120 & 1090 & 184 & 816 & 421 \\
6 & 21 & 411 & 82 & 770 & 28 & 435 & 345 & 548 & 1733 & 1414 & 118 & 76 & 218 \\
7 & 27 & 520 & 260 & 108 & 8 & 276 & 575 & 1300 & 1203 & 1203 & 127 & 48 & 162 \\
8 & 11 & 91 & 44 & 28 & 10 & 236 & 727 & 192 & 2310 & 866 & 148 & 11 & 75 \\
9 & 8 & 200 & 49 & 15 & 24 & 115 & 29 & 921 & 866 & 649 & 548 & 172 & 47 \\
10 & 41 & 461 & 40 & 75 & 15 & 167 & 659 & 2420 & 1690 & 1414 & 1203 & 110 & 114 \\
11 & 37 & 469 & 19 & 147 & 121 & 107 & 980 & 1986 & 2420 & 2420 & 1203 & 93 & 159 \\
12 & 135 & 1750 & 96 & 192 & 116 & 358 & 1120 & 2420 & 1624 & 1733 & 1300 & 111 & 338 \\
13 & 81 & 756 & 64 & 31 & 111 & 72 & 816 & 1553 & 1576 & 1300 & 980 & 236 & 146 \\
14 & 10 & 38 & 16 & 14 & 24 & 55 & 687 & 2420 & 657 & 1046 & 306 & 26 & 44 \\
15 & 19 & 74 & 21 & 18 & 152 & 248 & 1986 & 2420 & 761 & 1414 & 1300 & 73 & 113 \\
\hline
\end{tabular}

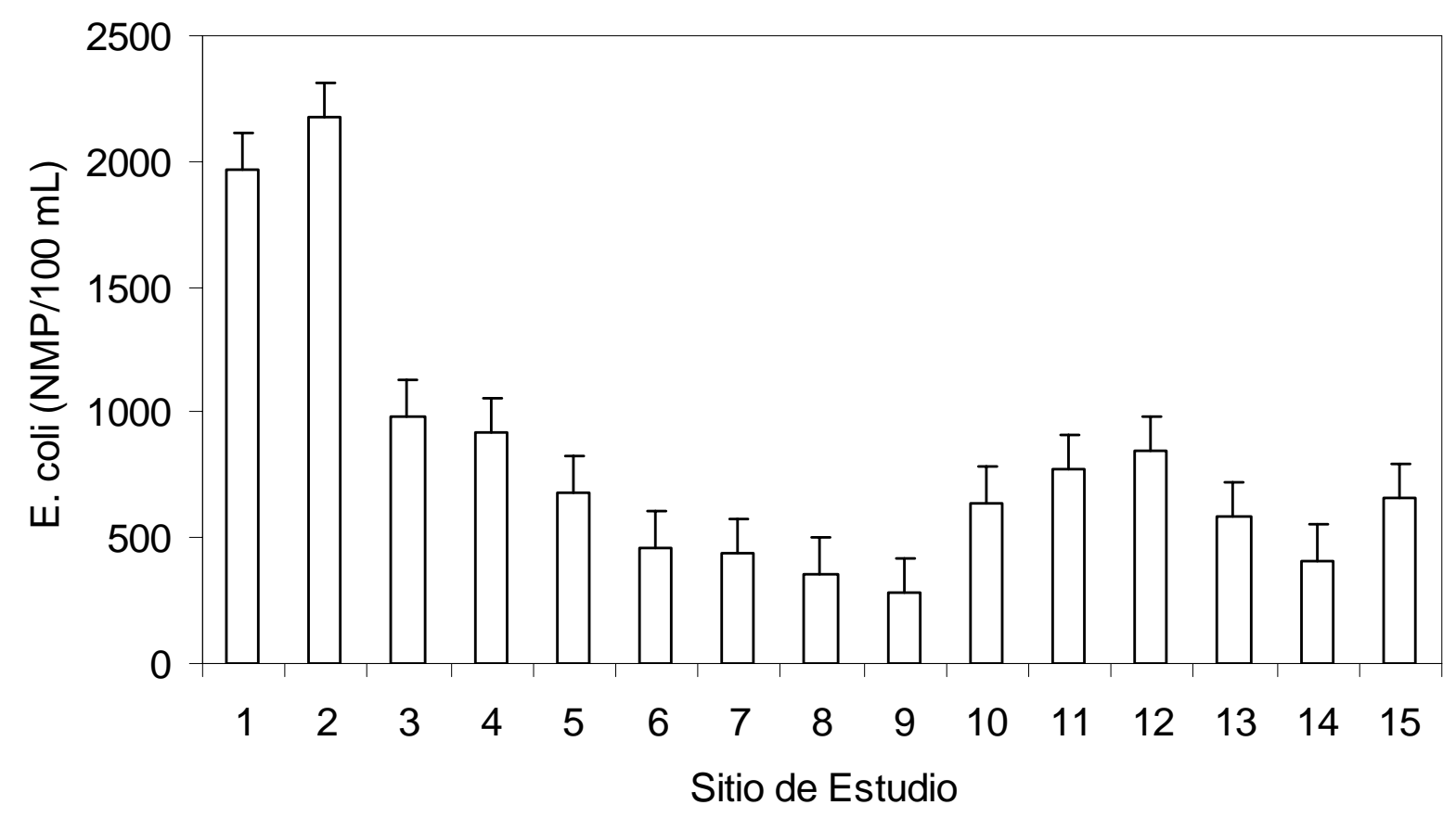

Fig. 2: Variación espacial de E. coli en el Río Hardy de febrero de 2006 a enero de 2007 
En la Fig. 3 se observa que en los meses de agosto a noviembre, la concentración de E. coli se mantuvo elevada en todo el río, lo cual coincide con el periodo de menor caudal de agua en el río $\left(0.449\right.$ a $\left.0.7 \mathrm{~m}^{3} / \mathrm{s}\right)$ (Fig. 4), de acuerdo con datos proporcionados por la Comisión Nacional del Agua (CNA, 2006), mientras que durante los meses de febrero a junio las concentraciones de $E$. coli fueron bajas y se relacionan con el mayor flujo de agua en el río, lo cual explica que la baja concentración de $E$. coli en este periodo obedece a un efecto de dilución de contaminantes. Por lo tanto, la variación temporal de la concentración de E. coli, se puede atribuir a la fluctuación en los flujos de agua en el río durante el año.

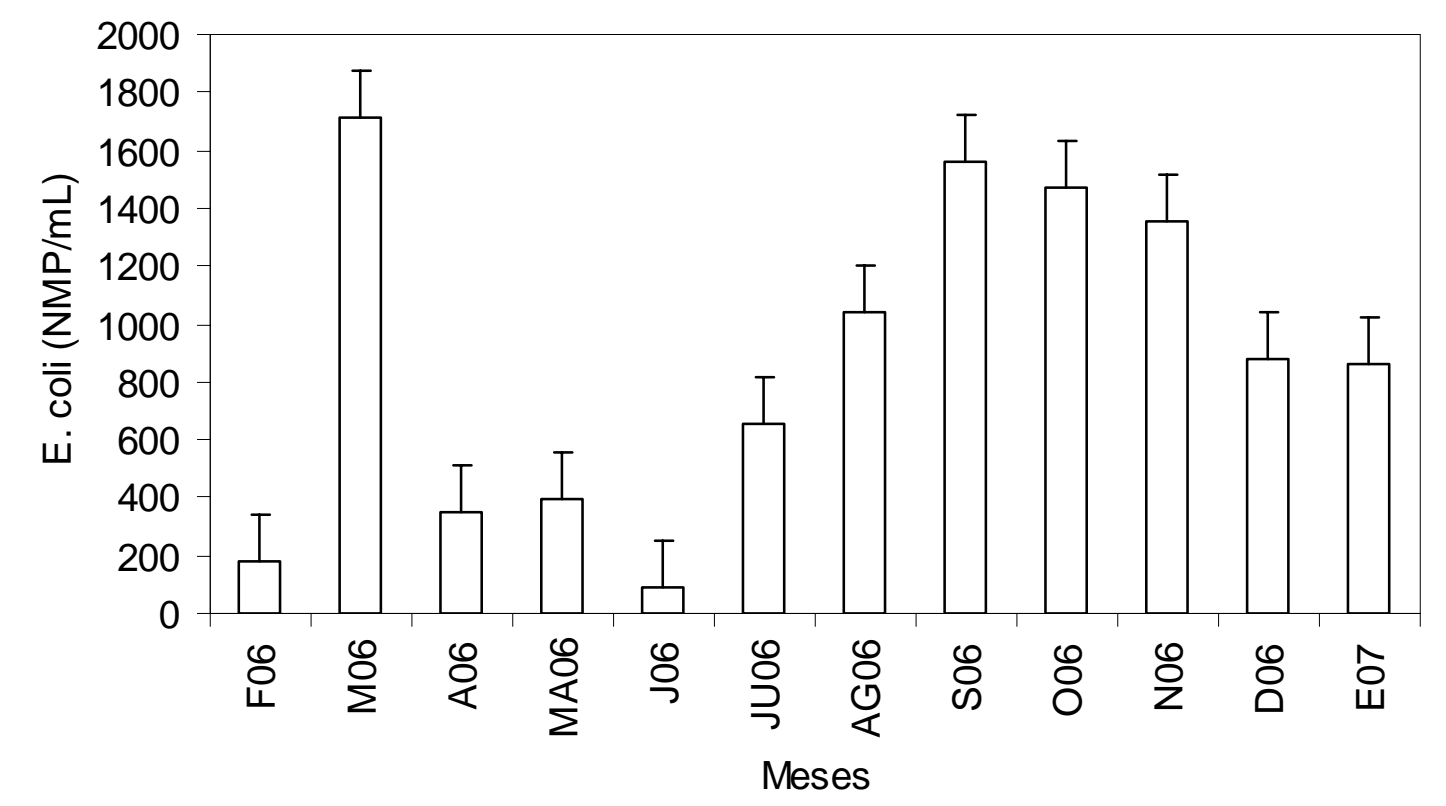

Fig. 3: Variación temporal de E. coli en el Río Hardy de febrero de 2006 a enero de 2007

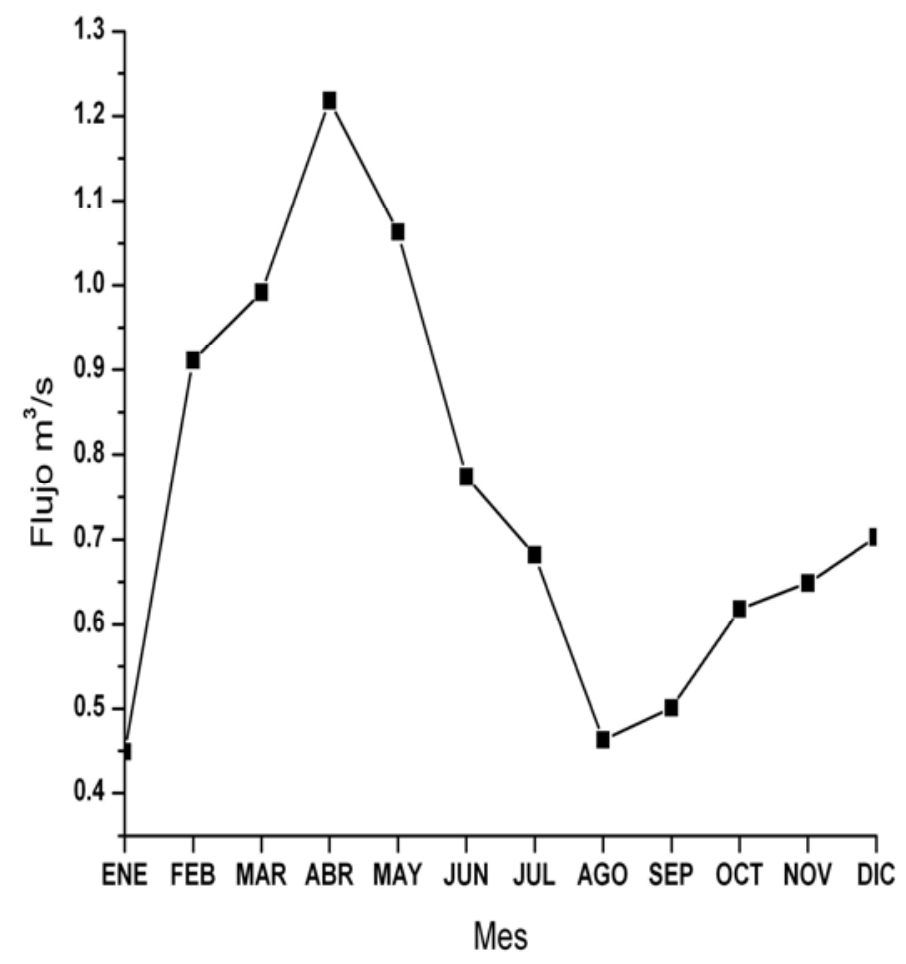

Fig. 4: Flujos de agua en el Río Hardy 
Parámetros físico-químicos

La caracterización física y química de los ríos es de gran relevancia para establecer planes de manejo, aunque se reconoce su debilidad para registrar cambios temporales y de su capacidad integradora a nivel ecosistémico (Figueroa, 2007). En la Tabla 2 se presentan los valores anuales promedio, máximos y mínimos de parámetros físico-químicos detectados en el río.

El Río Hardy presentó valores promedio de pH entre 8.0 y 8.4, con un valor mínimo de 7.2 y un máximo de 8.9. Estos variaron muy poco entre sitios de muestreo, registrándose los valores más altos en los meses de agosto a noviembre, entre 8.1 y 8.8. La temperatura promedio anual varió entre 20.6 y $25.7^{\circ} \mathrm{C}$, con un valor mínimo de $11.1^{\circ} \mathrm{C}$ y un valor máximo de $37.8^{\circ} \mathrm{C}$.

Tabla 2: Valores de parámetros físico-químicos, coeficientes de correlación entre parámetros físico-químicos y concentración de E. coli [NMP/100 mL] $(\mathrm{n}=178, \mathrm{p}=$ nivel de significancia)

\begin{tabular}{|c|c|c|c|c|c|c|c|c|c|c|c|c|}
\hline & \multicolumn{3}{|c|}{$\begin{array}{c}\mathrm{pH} \\
\text { [Unidades] }\end{array}$} & \multicolumn{2}{|c|}{$\begin{array}{l}\mathrm{OD} \\
{[\mathrm{mg} / \mathrm{L}]}\end{array}$} & & \multicolumn{3}{|c|}{$\begin{array}{c}\text { Temperatura } \\
{\left[{ }^{\circ} \mathrm{C}\right]}\end{array}$} & \multicolumn{3}{|c|}{$\begin{array}{l}\text { Cond. Eléctrica } \\
{[\mathrm{mS} / \mathrm{cm}]}\end{array}$} \\
\hline Sitio & Pron & Max & Min. & Prom. & Max. & Min. & Prom. & Max. & Min. & Prom. & Max. & Min. \\
\hline 1 & 8.4 & 8.8 & 7.3 & 9.3 & 13.4 & 4.3 & 25.7 & 37.8 & 15.6 & 12.7 & 18.9 & 6.2 \\
\hline 2 & 8.3 & 8.7 & 7.4 & 8.7 & 11.3 & 4.2 & 25.5 & 36.8 & 15.8 & 14.5 & 19.8 & 9.2 \\
\hline 3 & 8.3 & 8.7 & 7.9 & 8.9 & 15.8 & 4.4 & 23.5 & 31.5 & 16.3 & 11.3 & 17.5 & 5.4 \\
\hline 4 & 8.3 & 8.8 & 7.7 & 8.4 & 15.2 & 3.9 & 22.9 & 31.6 & 14.0 & 11.5 & 15.9 & 7.4 \\
\hline 5 & 8.3 & 8.8 & 7.9 & 8.9 & 15.1 & 4.0 & 23.0 & 30.9 & 14.1 & 10.9 & 13.0 & 7.6 \\
\hline 6 & 8.2 & 8.8 & 7.2 & 8.9 & 17.0 & 3.8 & 23.8 & 34.7 & 16.7 & 11.1 & 13.3 & 7.5 \\
\hline 7 & 8.3 & 8.8 & 7.2 & 8.8 & 17.5 & 4.1 & 24.0 & 33.4 & 14.4 & 11.0 & 13.6 & 7.3 \\
\hline 8 & 8.3 & 8.8 & 8.0 & 8.0 & 17.2 & 4.6 & 23.6 & 33.3 & 15.9 & 8.3 & 11.6 & 5.2 \\
\hline 9 & 8.3 & 8.8 & 7.9 & 7.0 & 16.8 & 4.1 & 23.7 & 30.9 & 13.5 & 8.6 & 11.1 & 6.0 \\
\hline 10 & 8.3 & 8.9 & 7.9 & 6.0 & 13.4 & 3.7 & 22.9 & 31.1 & 13.4 & 8.7 & 11.5 & 5.9 \\
\hline 11 & 8.2 & 8.8 & 7.7 & 6.3 & 14.5 & 3.4 & 22.4 & 30.0 & 12.5 & 8.9 & 11.5 & 5.9 \\
\hline 12 & 8.0 & 8.7 & 7.6 & 4.7 & 8.6 & 3.0 & 21.3 & 29.6 & 11.1 & 9.1 & 12.1 & 5.8 \\
\hline 13 & 8.1 & 8.7 & 7.5 & 4.4 & 8.5 & 2.5 & 20.8 & 29.3 & 11.6 & 9.1 & 12.7 & 5.8 \\
\hline 14 & 8.3 & 8.8 & 7.9 & 5.7 & 9.3 & 3.4 & 21.5 & 30.5 & 12.0 & 10.0 & 13.4 & 6.0 \\
\hline 15 & 8.2 & 8.7 & 7.7 & 4.9 & 8.6 & 2.5 & 20.6 & 30.1 & 11.4 & 11.3 & 17.2 & 6.1 \\
\hline \multirow[t]{2}{*}{ E. coli } & \multicolumn{3}{|c|}{0.52635} & \multicolumn{3}{|c|}{0.185528} & \multicolumn{2}{|c|}{-0.075947} & & \multicolumn{3}{|c|}{0.391397} \\
\hline & \multicolumn{3}{|c|}{$\mathrm{p}=.0422$} & \multicolumn{3}{|c|}{$p=.0135$} & \multicolumn{2}{|c|}{$p=.3145$} & & \multicolumn{3}{|c|}{$p=.0001$} \\
\hline
\end{tabular}

Los valores promedio de oxígeno variaron en un intervalo entre 4.4 y $9.3 \mathrm{mg} / \mathrm{L}$ con un valor mínimo de 2.5 y un máximo de $17.5 \mathrm{mg} / \mathrm{L}$. Los niveles más bajos de oxígeno se detectaron durante los meses de agosto a noviembre, periodo en que el río recibe los menores flujos de agua de drenaje agrícola y en que se registra los niveles más bajos de agua en el río. En los sitios 12, 13 y 15 detectaron valores de oxígeno abajo entre 2.5 y $5.0 \mathrm{mg} / \mathrm{L}$ durante todo el periodo de estudio y se presentaron bajos niveles de agua con zonas de estancamiento la mayor parte del año. Valores 
menores de $3.5 \mathrm{mg} / \mathrm{L}$ de oxígeno, pueden ser peligrosos para la vida acuática y se asocia a alta demanda de DBO y a bajos caudales, al respecto, Álvarez et al (2008), asociaron valores de 5.78 $\mathrm{mg} / \mathrm{L}$ de oxígeno con zonas de almacenamiento de agua y con poca aereación. Se ha señalado en la literatura (Nelson et al, 2009) un valor de $5 \mathrm{mg} / \mathrm{L}$ como valor mínimo para la protección de la vida acuática.

Los valores promedio de conductividad eléctrica variaron en un intervalo entre 8.3 y $14.5 \mathrm{mS} / \mathrm{cm}$, presentándose los valores máximos durante los meses de agosto a noviembre (15 a $19 \mathrm{mS} / \mathrm{cm})$, periodo que corresponde a la época de aguas bajas. Es importante resaltar que durante este mismo periodo también se presentaron las concentraciones más altas de $E$. coli en todo el río. A este respecto Chalarca et al (2007), también señalan un incremento en la conductividad eléctrica en la época de aguas bajas e indican que el incremento en las concentraciones de iones en esta época puede deberse al aumento en las tasas de descomposición de la materia orgánica.

De acuerdo a los resultados obtenidos del análisis de Pearson, se observa que estadísticamente la conductividad eléctrica presentó una correlación con la concentración de $E$. coli $(r=0.39)$, altamente significativa $(\mathrm{P}<0.001)$. Esto puede deberse al arrastre agrícola, puesto que aumenta la conductividad junto con la concentración de E. coli, lo que sugiere que la calidad bacteriológica del agua depende más de la calidad de las descargas que del cuerpo de agua. Esto también puede explicar que la concentración de bacterias es más alta en los sitios cercanos a las descargas hacia el río. Se observa que la concentración de $E$. coli no se correlacionó con el pH, la temperatura ni con el oxígeno disuelto.

\section{CONCLUSIONES}

La concentración de $E$. coli fue significativamente diferente en los sitios 1 y 2 respecto a los trece restantes y en algunos sitios se detectaron niveles hasta diez veces por arriba del LMP. Los valores más altos se presentaron en la parte alta del río, que comprende el tramo donde descargan los drenes agrícolas.

De los quince sitios estudiados, sólo cinco cumplieron con el LMP de $126 \mathrm{NMP} / 100 \mathrm{~mL}$. De los cinco sitios que si cumplieron, tres corresponden a sitios designados para actividad recreativa, siendo éstos; los sitios 8, 9 y 10. Durante el periodo de agosto a noviembre la concentración de $E$. coli se elevó en todo el río a niveles arriba del límite recomendado. Mientras que a partir de diciembre en que inician los riegos y los flujos de agua en el río aumenta, se observa una marcada atenuación de la contaminación bacteriana por efecto de dilución. Dentro de los sitios que no cumplieron con el LMP se encuentran los sitios 7 y 11.

Actualmente el Río Hardy está siendo afectado por la contaminación de agua residual agrícola, doméstica y pecuaria. Debido a la carencia de datos de calidad de agua anteriores a los obtenidos en este estudio, se recomienda continuar con el monitoreo de la calidad del agua, para tener información que permita tomar acciones para proteger la salud de los usuarios, además de establecer un control de las descargas de agua antes de ser vertidas al río, principalmente las que son de origen doméstico.

\section{AGRADECIMIENTOS}

Al CONACYT por el apoyo para la realización de estudios de doctorado del primer autor. A la UABC y a la COCEF por los apoyos financieros otorgados para la realización de este estudio. A las ONG's: Sonoran Institute, AEURHYC y PROESTEROS, por los apoyos logísticos y técnicos proporcionados.

\section{REFERENCIAS}

Álvarez, J.P., J.E. Panta., C.R. Ayala y E.H. Acosta, Calidad Integral del Agua Superficial en la Cuenca Hidrológica del Río Amajac, Información Tecnológica, ISSN: 0718-0764 (en línea), 19(6), 2008. http:www.scielo.cl/scielo.php. Acceso: 16 de Diciembre (2009). 
CNA, Reporte Técnico de los Flujos de Agua que Entran al Hardy, Comisión Nacional del Agua, Distrito de Riego 014, Península de Baja California Región I. (2006).

Chalarca, D.A., R. Mejía y N.J. Aguirre, Aproximación a la Determinación del Impacto de los Vertimientos de las Aguas Residuales Domésticas del Municipio de Ayapel, sobre la Calidad del Agua de la Ciénaga, Revista Facultad de Ingeniería Universidad de Antioquia, ISSN: 0120-6230 (en línea), 40, 2007. http://www.scielo.cl/scielo.php. Acceso: 4 de Enero (2010).

Doménech-Sánchez, A., F. Olea y C.I. Berrocal, Infecciones Relacionadas con las Aguas de Recreo, Enferm. Infecc. Microbiol. Clín.: 26(13), 32-37 (2008).

Dwight, R.H., D.B. Baker., J.C. Semenza y B.H. Olson, Health Effects Associated With Recreational Coastal Water Use: Urban Versus Rural California, American Journal of Public Health: 94(4), 565-567 (2004).

Figueroa, R., A. Palma., V. Ruíz y X. Niell, Análisis Comparativo de Índices Bióticos Utilizados en la Evaluación de la Calidad de las Aguas en un Río Mediterráneo de Chile: Río Chillán, VIII Región, Rev. Chil. Hist. Nat. ISSN: 0716-078X (en línea), 80(2), 2007. http://www.scielo.cl/scielo.php. Acceso: 5 de Enero (2010).

IDEXX, Método Quanty-Tray/2000 para Determinación de Coliformes Totales y E. coli, IDEXX Laboratories, Inc., (en línea) 2003. www.idexx.com/water. Acceso: 20 de Junio (2009).

Rivera, N.R., F. Encina., R. Palma y P. Mejias, La Calidad de las Aguas en el Curso Superior y Medio del Río Traiguén. IX Región-Chile, Información Tecnológica. ISSN: 0718-0764 (en línea), 20(1), 2009. http://www.scielo.cl/scielo.php. Acceso: 17 de Diciembre (2009).

Papovicova, J., Water Quality Assessment of Prairie Creek Reservoir in Delaware Country, Indiana, Proceedings of Indiana Academy of Science: 117(2), 124-135 (2008).

Pruss, A., Review of Epidemiological Studies on Health Effects from Exposure to Recreational, International Journal of Epidemiology: 27(1), 1-9 (1998).

Saracho, M., L. Segura., P. Moyano., N. Rodríguez y E. Carignano, Calidad del Agua del Río del Valle Catamarca, para uso Recreativo, Revista de Ciencia y Tecnología: 12, (2006).

USEPA: Water Quality Standards for Coastal and Great Lakes Recreation Waters; Final Rules, Part II. Environmental Protection Agency. 67218 Federal Register/Vol. 69, No. 220/Rules and Regulations, 2004 (en línea) http://www.epa.gov. Acceso: 18 de Diciembre (2009).

USEPA: 40 CFR Parts 136 and 503. Guidelines Establishing Test Procedures for the Analysis of Pollutants in Wastewater and Sewage Sludge; Final Rule, Part III. Environmental Protection Agency 14220 Federal Register/Vol. 72, No. 57/Rules and Regulations, 2007 (en línea) http://www.epa.gov. Acceso: 18 de Diciembre (2009).

Wade, T. y otros 6 autores, Rapidly Measured Indicators of Recreational Water Quality of SwimmingAssociated Gastrointestinal IIIness, Environmental Health Perspective, 114(1), 24-28 (2006). 
